\title{
Emancipação, a cena e o espectador em jogo
}

\section{Resumo}

$\mathrm{O}$ artigo trata das articulações entre as proposições de Bernard Dort e Jacques Rancière quanto à noção de emancipação. Se, a partir da década de 1980, a cena foi surpreendida pelo primeiro como no rumo da emancipação, essa articulação poética convida o espectador a experimentar outras disposições e sentidos que possam leva-lo a imaginar outros modos de interação social, como pensado por Rancière. Através de sentidos agora fundados na noção de jogo.

Palavras-chave: Bernard Dort; Emancipação; Jacques Rancière; Jogo.

\section{Abstract}

The article isfocused in Bernard Dort and Jacques Rancière articulations around emancipation concept. If after 1980' scene was taken for the first as in the emancipation ways, these poetic articulations invite the spectator to experiment other senses and dispositions that can lead to other social interaction ways, as thought by Rancière. Now, by the senses of roles play.

Keywords: Bernard Dort; Emancipation; Jacques Rancière; Play.

Lançado em 1988, um escrito de Bernard Dort funcionou como farol e como oráculo para o teatro desenvolvido na década seguinte: $A$ representação emancipada. Nela, o teórico e crítico francês desenvolveu vigorosos raciocínios analíticos que apontavam os inéditos rumos tomados pela cena ocidental, destacando especialmente os novos avatares que passavam a reger, desde aquela década, a própria noção de teatro. Vinte anos depois surge $O$ espectador emancipado, conjecturas do filósofo Jacques Rancière voltadas a examinar as novas condições propostas àqueles que se alojam nas plateias da nova cena.

Existem, entre os dois textos, inúmeros liames estruturais, ainda que Rancière não se reporte diretamente à obra de Dort para estabelecer suas proposições. Uma primeira observação desperta nosso interesse: os dois títulos grafam a expressão "emancipação"; e, certamente, não se trata de coincidência ou espelhamento. Ela indica um novo patamar para a consciência, outra atitude para com a reflexão e os paradigmas nela mobilizados. O conceito de emancipação evoca, primariamente, o vocabulário político, referindo o regime que une - ou desune - uma matriz e uma 
colônia, marcando aquele instante em que a segunda, mais do que simplesmente promover sua independência em relação à primeira, alcança sua alforria em termos de identidade e formulações estruturais. A emancipação envolve os padrões intelectuais e de referência, evidenciando o verdadeiro caráter do corte epistemológico efetivado.

As duas obras, portanto, querem se posicionar na dupla condição de abordagens estéticas a partir de um olhar político; ou, conforme outro entendimento, não desvincular as duas instâncias nas quais a cena teatral é produzida, dada sua arraigada condição social.

Como entender, todavia, o alcance e as implicações dessa emancipação? Em 0 inconsciente estético, Rancière havia flagrado como a arte, em seu desenvolvimento histórico, promovera uma ruptura entre o pensado e o não pensado, entre o falado e o escrito. O grande paradigma que sustenta o primeiro estatuto da palavra é o logos grego, articulação transparente entre quem fala e o que fala. Na representação clássica, como constatada por Foucault em As Palavras e as Coisas, não há intervalo entre uma coisa e outra: a um só tempo, o logos é uma verdade enunciada e uma asseveração de conduta por parte de quem o articula, criando um vínculo indissolúvel entre os dois regimes. Assim, como adverte Rancière, "essa 'palavra viva' é identificada à grande palavra que se faz ato: a palavra viva do orador que perturba e persuade, edifica e arrebata as almas e os corpos. É também, concebida sobre seu modelo, a palavra do herói trágico que vai até o fim de suas vontades e paixões" (RANCIÈRE, 2009, p.34).

Com a autonomia da arte, a palavra perderá essa transparência imanente, dificultando-se estabelecer os limites entre o pensado e não pensado, uma vez que ela se cala. Escapando dos paradigmas hegemônicos, subvertendo o logos, a palavra torna-se opaca, resistente e dura, remetendo mais ao corpo que à inteligência:

\footnotetext{
A escrita muda, num primeiro sentido, é a palavra que as coisas mudas carregam elas mesmas. É a potência de significação inscrita em seus corpos, e que resume o 'tudo fala' de Novalis, o poeta mineralogista. Tudo é rastro, vestígio ou fóssil. (RANCIÈRE, 2009, p. 35).
}

Em tal inovadora cartografia sócio-estética de fenômenos, o artista tem seu registro alterado, deixando para trás a imagem clássica de conciliação para aproximar-se da imagem moderna de expedicionário, de investigador, de catalogador. Se o mundo tornou-se um grande labirinto, o artista nele perquire possíveis caminhos e veredas, nem sempre alcançando o umbral de sua saída. Assim,

O artista é aquele que viaja nos labirintos ou nos subsolos do mundo social. Ele recolhe vestígios e transcreve os hieróglifos pintados na configuração mesma das coisas obscuras ou triviais. Devolve aos detalhes insignificantes 
da prosa do mundo sua dupla potência poética e significante. (RANCIÈRE, 2009, p. 36).

A cena teatral dos anos de 1980 costuma ser referida como aquela aberta ao delírio imaginário dos grandes encenadores, que operaram um progressivo descolamento entre texto e imagem. Dort salienta como, ao longo do século, esse percurso veio sendo adubado pelo progressivo desenvolvimento da encenação, de Wagner a Craig, ganhando nas primeiras décadas do século XX suas mais sólidas ferramentas de desenvolvimento, com os trabalhos de Antoine, Stanislávski, Meyerhold, Fuchs, Reinhardt, entre outros. Assim, no apogeu desse movimento, ao se esgotarem todas as experiências levadas a efeito pelas vanguardas históricas, a cena tornara-se um exato flagrante daquele labirinto evocado por Rancière, um laboratório de investigação e um território para confrontos e disputas. Com a Guerra Fria, a crescente ideologização dos anos 1960 e o início da crise internacional deslanchando a partir da década seguinte, a semiologia teatral tornou-se uma nova referência quer para a análise, quer para a confecção dos novos formatos cênicos. Tal processo, acumulativo e crescente, irá explodir exatamente ao longo dos anos de 1980. Razão pela qual, para Dort,

O que interessa hoje no teatro é justamente o modo de relação que se institui entre os elementos relativamente autônomos da representação: o texto, o espaço, a representação do ator, o tempo. (...) A essência do teatro não é que o texto seja representado, mas uma interação de todos os elementos que o constituem, uma espécie de prova por que passam os elementos, uns perante os outros. (...) é um combate entre os diversos elementos que se confrontam e afrontam e de certo modo entram em conflito (DORT, 1988, p. 133).

Ou seja, estamos diante de uma cena que, mais do que erigir um discurso - um logos -, evoca, antes, suas contradições, seus desvãos, suas incongruências. Trata-se de

Uma competição que ali tem lugar, uma contradição que se explicita diante de nós, espectadores. A teatralidade, então, não é mais somente a 'espessura de signos' de que falava Roland Barthes. Ela é também o deslocamento desses signos, suas conjunções impossíveis, seus confrontos diante do olhar do espectador dessa representação emancipada (DORT, 1988, p. 183).

Tal emancipação da representação alcançou, assim, nos termos antes enunciados por Rancière, seu direito à obscuridade, a ser labiríntica, enovelar-se sobre si mesma e despregar-se dos anteriores paradigmas que clamavam por clareza ou transparência enquanto fundamentos (especialmente ideológicos) de seu estatuto. $E$ o faz com o alarido de uma sinfonia, uma nova arquitetônica discursiva que possa abrigar não apenas a pluralidade de seus agentes como, especialmente, a densidade das vozes que a compõem. A noção bakthiniana de polifonia é explicitamente evocada por Dort: 
Definitivamente, o que nós assistimos hoje é a uma emancipação de diferentes fatores da representação teatral. Uma concepção unitária do teatro, seja ela baseada no texto ou na cena, está em vias de apagar-se. Ela deixa progressivamente espaço para a ideia de uma polifonia, e mesmo para uma competição entre as artes irmãs que contribuem para o fazer teatral. [...] É a representação teatral como jogo entre as práticas irredutíveis de um ao outro e, todavia, conjugadas como momento onde eles se confrontam e questionam, como combate mútuo no qual o espectador é, no final das contas, o juiz e o que está em jogo, que a partir de agora deve-se tentar pensar (DORT, 1988, p. 187).

Emancipada a cena, restava emancipar o espectador. Até o teatro clássico, a cena ocidental, dos gregos até Diderot, estivera envolvida com a concretização de um pathos, seu formato enquanto logos cênico. O romantismo iniciara aquele processo de ruptura, que o realismo e o naturalismo irão levar até seus estertores. De modo que, até meados do século $\mathrm{XX}$, a grande batalha cênica esteve organizada em torno da ilusão. Siderado por ela, o espectador fora considerado uma vítima sua: aplastado em sua cadeira, afundado na escuridão, entregue ao solilóquio com seus fantasmas, era ele um refém, um detido ad judice.

Tal situação não era exclusiva da cena teatral, mas uma condição verificável igualmente na grande cena da configuração social. Denominada sociedade do espetáculo por Guy Dèbord, as culturas ocidentais conheceram um crescente mergulho na alienação e naquilo que Marx denominara fetichismo da mercadoria, a inversão decorrente entre o valor de troca e o valor de uso dos produtos. A conjunção dos dois fatores produziu um estreitamento na apreensão do real, tornando o quase que separa a coisa de sua representação praticamente não mais existente - o que abriu caminho para o triunfo da ilusão. Em seu crescente refinamento expressivo, a arte, auxiliada por meios técnicos e tecnológicos, alcançou um alto grau de verismo e, daí, a concretude da ilusão por ela veiculada.

De modo que uma equação estética interliga verismo e ilusão, assim como distanciamento e desalienação, fazendo esses quatro termos/conceitos conhecerem diversos expedientes operativos entre si que ora reforçam ora anulam um ao outro. Foi por isso que diversos artistas e críticos teatrais destacaram a condição de passividade do espectador, clamando por outros recursos cênicos que pudessem ou libertá-lo dessa clausura ou fornecer-lhe os meios para tanto.

A partir dos anos 1960 o espectador passa a ser considerado um dos polos de atenção dentro da criação artística e, igualmente, das preocupações evidenciadas por críticos e teatrólogos. Naquele momento, duas alternativas organizavam a pluralidade 
dos discursos em voga: a proposta brechtiana e a artaudiana. A primeira prometia levar às benesses do socialismo, onde toda alienação estaria desfeita e os homens poderiam ser livres; a segunda apontava os arcaicos caminhos da coreia e do coletivismo, os fraternos braços e abraços que estavam na base dos rituais e demais efusões assemelhadas. Ambas apontavam para uma comunidade - utópica ou real, não importa - tida como porto seguro para albergar o pobre espectador vitimado pela ilusão e suas desventuras.

Nas duas alternativas em curso naquele momento, procedimentos pedagógicos foram mobilizados, a partir de paradigmas sobejamente conhecidos:

No esquema pedagógico, o ignorante não é apenas aquele que não conhece aquilo que ele não conhece; mas também aquele que ignora como conhecer. O mestre não é apenas aquele que sabe precisamente o que permanece desconhecido para o ignorante; ele também sabe como fazer com que isto seja conhecível, a tal hora e em tal lugar, de acordo com tal protocolo (RANCIĖRE, 2010, p. 112).

Esse era o formato de logos com que essas duas alternativas se apresentavam, seja no Berliner Ensemble (templo vivo do pensamento marxiano de Brecht), seja no Living Theatre (altar contracultural que propunha o ritual como modelo salvífico para suas plateias). Ora, seja por uma ou outra via, ambos os discursos apontavam um futuro como ponto ótimo de chegada, desde que o processo pedagógico fosse seguido à risca. Por vias diferentes e com distintos propósitos, ambos não se desfizeram da noção de poder como limite último de suas considerações. Assim, supunham uma libertação, mas não uma emancipação. A emancipação não é apenas uma independência, retirar o espectador de sua cadeira. "Emancipação é o processo de verificação da igualdade de inteligência", grifa o filósofo, mas uma igualdade em todas as suas manifestações:

O animal humano aprende tudo do mesmo modo que aprendeu a sua língua materna, como se aventurou pelas florestas das coisas e signos que o rodeiam para assumir seu lugar entre seus companheiros humanos - observando, comparando uma coisa com a outra, um signo com um fato, um signo com outro signo, e repetindo as experiências que ele encontrou por acaso (RANCIĖRE, 2010, p. 113).

É a tradução, o grande trabalho poético em qualquer aprendizado. Assim, trabaIhar no rumo da emancipação do espectador não implica em retirá-lo da cadeira e fazê-lo tomar a cena, no lugar dos atores ou junto a eles. Ninguém vai ao teatro para subir ao palco - ao menos não deveria ir -, mas para partilhar uma experiência de tradução em comum, o que demanda um intelecto ativo e uma sensibilidade desperta, onde o espectador possa "fazer seu poema com o poema que é feito diante dele". 
É nesse ponto em que a cena emancipada, como surpreendida por Dort, possibilitou fossem criadas as condições para a emancipação do espectador, flagrada por Rancière. Na primeira, a cena se dá a ver enquanto linguagem em operação, no momento mesmo em que todos os seus signos constituintes estão em ebulição, em processo, em nascimento; não enquanto estatuto de logos, mas de metábole. E quanto ao espectador, ao estar diante de tal cena, ele é convidado a organizar e interpretar os sentidos ali verificados, traduzindo os signos ali em evidência nos termos de suas próprias experiências e inteligência. Mesmo sentado inicia-se para ele, então, o jogo.

\section{Referências Bibliográfica}

DORT, Bernard. La representation emancipée. Arles: Act Sud, 1988.

RANCIÈRE, Jacques. O inconsciente estético. São Paulo: Editora 34, 2009.

Le spectateur emancipé. Paris: La Fabrique, 2008. 